\title{
Book review on "Uncertainty in Acoustics: Measurement, Prediction and Assessment" by Robert Peters
}

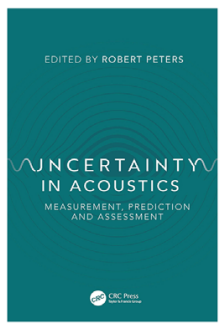

\author{
First Edition, First Published 2020, \\ eBook Published 27 July 2020 \\ CRC Press, 464 pages \\ DOI: https://doi.org/10.1201/9780429470622 \\ eBook ISBN: 9780429470622
}

"A measurement result is complete only when accompanied by a quantitative statement of its uncertainty". [Stephanie Bell in the Measurement Good Practice Guide No. 11, A Beginner's Guide to Uncertainty of Measurement, National Physical Laboratory, issue 2, 2001)]

There can be no better motivation to read this book. It is dedicated to, but also essentially initiated by, Dr Robert Peters, who, to the great dismay of all colleagues who worked with him, passed away in 2019.

Robert Peters has made significant contributions to acoustics, particularly to education in acoustics at several British universities. He was also very active in the Institute of Acoustics, and in the UK acoustics community in general. Among his last projects was this book about uncertainty in acoustics which was finally finished under the technical editorship of Keith Attenborough.

This book is unique. It is written by 13 authors, each focusing in specific aspects of uncertainty in acoustics. It contains a wealth of valuable fundamentals of uncertainty quantification, minimisation and evaluation of such uncertainties in acoustical measurements. It contradicts the (bad) joke of experimental physicists "never repeat a successful measurement". Of course, today even more than ever, experimental results shall be well-documented and reproducible. Reproducibility, however, requires information about the uncertainties in order to decide whether or not the results are significantly consistent. This is why the book is extremely relevant!

For all areas of sound and vibration, especially in noise control, it will be a reference book for anyone doing experimental work, laboratory or field tests. Although a basic knowledge of statistics will be beneficial, the book is written in a sufficently clear way that the equations behind statistical distributions and uncertainty propagation can be well understood.

The content is organised as follows: Introduction and Concepts (John Hurll), Introduction to Uncertainty in Acoustic Measurements (Robert Peters), Measurement Uncertainty Associated with Sound and Vibration Instrumentation (Ian Campbell), Uncertainty in the Prediction of Sound Levels (Roger Tompsett), Uncertainty in Environmental Noise Measurement (David Waddington and Bill Whitfield), Uncertainty in Room Acoustics Measurements (Adrian James), Speech Transmission Index (STI): Measurement and Prediction Uncertainty (Peter Mapp), Uncertainty Associated with the Measurement of Sound Insulation in the Field (Bill Whitfield), Uncertainty in Measuring and Estimating Workplace Noise Exposure (Philip Dunbavin), Uncertainty in the Measurement of Noise Emission from Plant and Machinery (Robert Peters), Uncertainty in the Measurement of Vibration Levels (Jorge D'Avillez and Robert Peters), Uncertainty in Prediction of Rail-induced Ground-borne Vibration (Jorge D'Avillez), Managing Uncertainty in Noise Assessment Processes (Colin Cobbing and Charlotte Clark) Uncertainty in International Acoustics Standards (Doug Manvell).

Examples and references to standard test methods also make the book a valuable source of information and guidance. So it should be of highest interest for everybody doing acoustic measurements, the student as well as the acoustical engineer.

Michael Vorländer

Cite this article as: Vorländer M. 2021. Book review on "Uncertainty in Acoustics: Measurement, Prediction and Assessment" by Robert Peters. Acta Acustica, 5, 23. 